\title{
Calibration AND ASSESSMent OF LoW-COST DuSt SENSORS
}

\author{
Adnan Masic, Boran Pikula, Dzevad Bibic, Rajfa Musemic \& Almin Halac
}
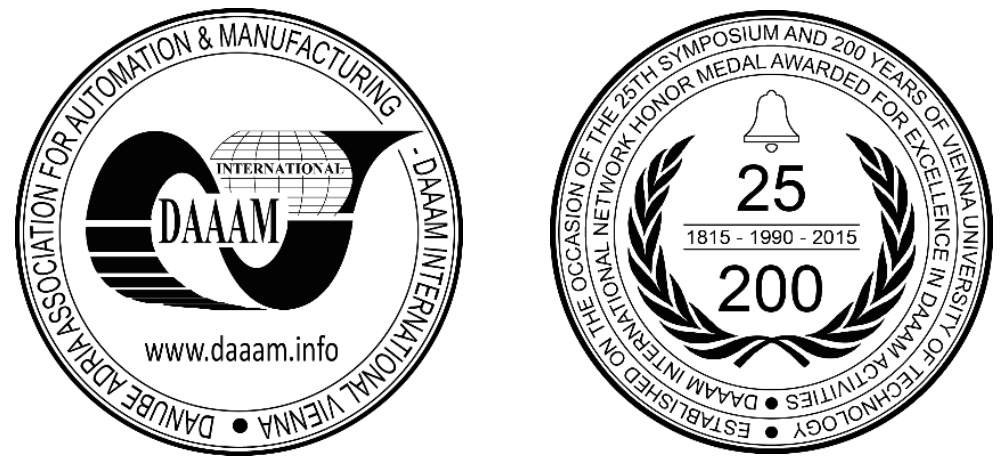

This Publication has to be referred as: Masic, A[dnan]; Pikula, B[oran]; Bibic, D[zevad]; Musemic, R[ajfa] \& Halac, A[lmin] (2018). Calibration and Assessment of Low-Cost Dust Sensors, Proceedings of the 29th DAAAM International Symposium, pp.0523-0528, B. Katalinic (Ed.), Published by DAAAM International, ISBN 978-3-902734-20-4, ISSN 1726-9679, Vienna, Austria

DOI: $10.2507 / 29$ th.daaam.proceedings.075

\begin{abstract}
Air pollution with particulate matter (PM) represents major risk for humans' health. Important step towards the solution of the aforementioned problem is the correct measurement of PM concentrations in the air. Commodity (low-cost) sensors are very popular nowadays, since they are affordable and they fit well in the trend called Internet of Things (IoT). However, measurement of PM concentrations in the air is difficult task and low-cost sensors are unable to provide accurate readings out of the box. Thus, advanced calibration is necessary for any application of low-cost dust sensors. In this paper we propose calibration technique and discuss initial results.
\end{abstract}

Keywords: low-cost sensors; particulate matter; air pollution; calibration; humidity corrections

\section{Introduction}

Air pollution is one of the greatest problems of the mankind. Very small particles and liquid droplets suspended in the air represent major risk for humans' health. Once inhaled, these particles can affect the heart and lungs and cause serious health effects. The size of particles is directly linked to their potential for causing health problems. The particles smaller than 10 micrometers (PM10) in diameter pose the greatest problems, because they can get deep into the lungs, and some may even get into the bloodstream. Numerous scientific studies have linked particle pollution exposure to a variety of problems, including:

- $\quad$ premature death in people with heart or lung disease,

- nonfatal heart attacks,

- irregular heartbeat,

- aggravated asthma,

- decreased lung function,

- $\quad$ increased respiratory symptoms, such as irritation of the airways, coughing or difficulty breathing.

People with heart or lung diseases, children, and older adults are the most likely to be affected by particle pollution exposure [1]. The measurement of PM10 concentration in the air is very important step towards the solution of the particle pollution problem. 
But it's a challenging and generally expensive task. Recently, alternative, low-cost methods were developed. These methods, if implemented correctly, could open entirely new field in the air pollution research. Another implication of the proposed method is the reduction of inequality regarding the air pollution (i.e. the gap between rich and developing countries, which is evident). The most promising low-cost method of measurements of PM10 concentration is optical technique, using the laser scattering on the particles. Basic principle of work of typical optical particle sizer is depicted in figure 1 [2].

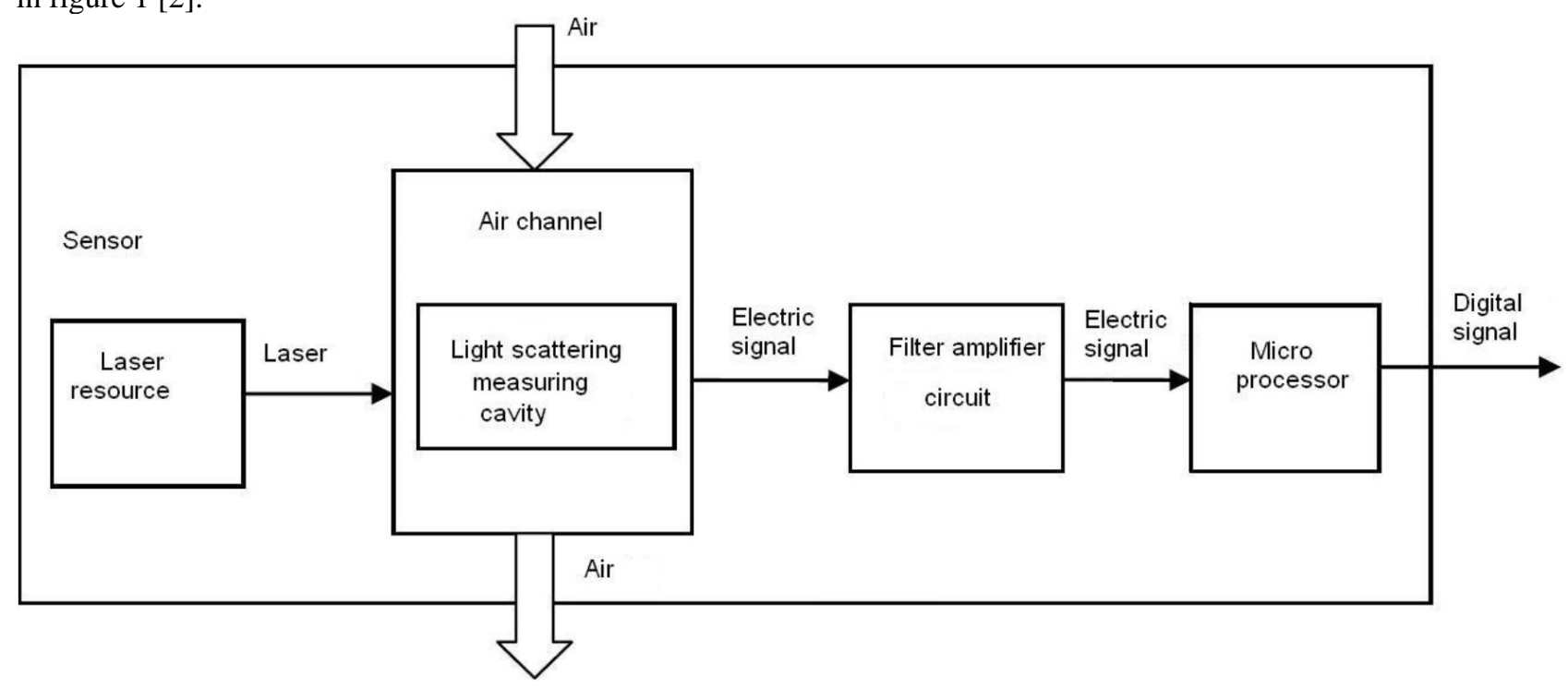

Fig. 1. Block diagram of the optical particle sizer

Laser light is scattered on the particulate matter in the air (aerosols), producing certain effect on the photo-detector in the sensor. Electric signal from the photo-detector is amplified and processed internally using the Mie theory [3]. In short, the Mie theory is the solution of Maxwell's equations in the case of scattering of an electromagnetic plane wave by a homogeneous sphere. The theory assumes that

1. all particles are spherical, optically homogenous and isotropic,

2. particles are illuminated by a plane wave of known wavelength,

3. the refractive index of both particle and medium (air) is known,

4. there is neither surface charge nor surface current on particles.

These assumptions should be carefully examined, since they can lead to significant uncertainty in the measuring process. Furthermore, the density of the particles must be assumed in order to calculate result in desired units $\left(\mu \mathrm{g} / \mathrm{m}^{3}\right)$. Quality of PM concentration measurements using the optical sensors can be improved using the recommendations from the ISO standard 13320:2009 [4].

Yet another effect greatly affects the performance of the optical particulate matter sensors: the hygroscopic growth of aerosols. In the situations where relative humidity $(\mathrm{RH})$ is very high, direct reading from such sensors may be very inaccurate [5]. Appropriate correction for RH influence on the PM sensor is required [6], [7].

\section{Field campaign}

In order to assess performance of optical PM sensors, we have developed data acquisition system (DAS), with PMS5003 sensor from Plantower, China. In-house developed DAS called MAQS (Mobile Air Quality System) was based on our previous work [8], [9]. We have chosen two locations for measurements: one in the urban part of Sarajevo city (Otoka), and another in suburban part (Ilijaš). These two MAQS sensors were installed as close as possible to the available governmental stations, that use reference devices which work on the princple of the attenuation of beta radiation (Beta-Attenuation Monitor, BAM). Figure 2 shows the map with locations of MAQS sensors and governmental BAM monitors nearby. In case of Otoka, MAQS sensor was about 350 meters away from BAM monitor, while in Ilijaš the distance was about 200 meters. Strictly speaking, we can't say that sensors were collocated, but it is highly unlikely that the atmosphere differs in such a short distance. Very localized sources of pollution can affect comparison of BAM and MAQS sensors, though.

BAM monitors have heated inlets, and they are not affected by humidity effects. For our system, we have adopted the following correction factor $(\mathrm{CF})$ for relative humidity $(\mathrm{RH})$ :

$\mathrm{CF}=\left\{\begin{array}{r}1 \text { for } \mathrm{RH} \leq 80 \% \\ \text { linear increase from } 1 \text { to } 13 \text { for } 80 \%\end{array}\right.$

linear increase from 1 to 1.3 for $80 \%<\mathrm{RH}<100 \%$ 
If the direct reading from the MAQS sensor is PM10, then the corrected value PM10* would be

$\mathrm{PM}^{*}=\frac{\mathrm{PM} 10}{\mathrm{CF}}$

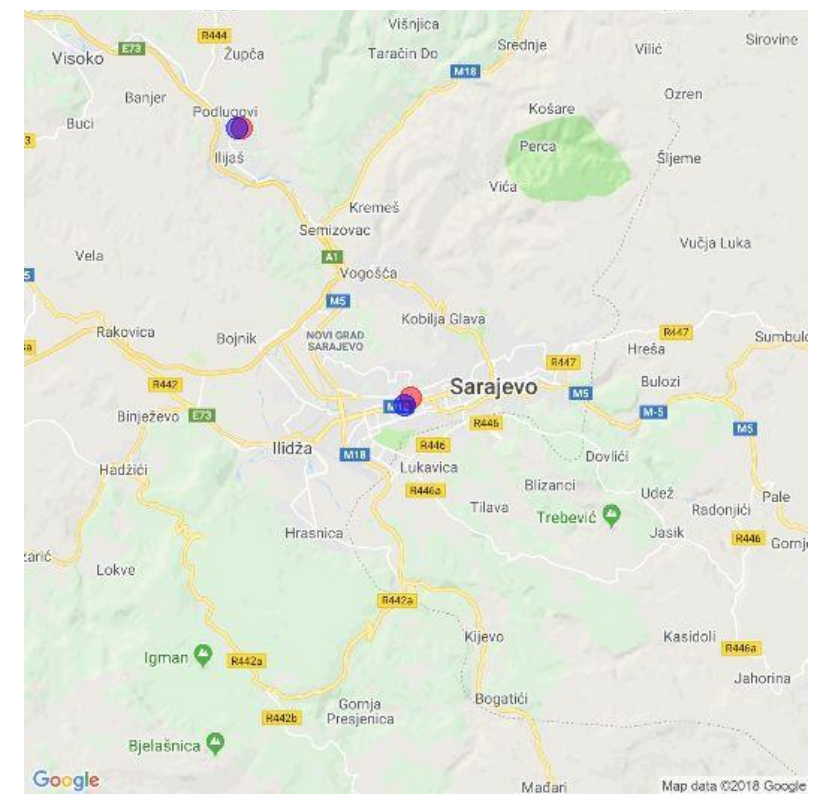

Fig. 2. Locations of MAQS sensors (red circles) and governmental BAM monitors (blue circles)

\section{Results}

We have collected continuous measurements at urban location (Otoka) from 18/8/2018 until 13/10/2018 and at suburban location (Ilijaš) from 12/8/2018 until 5/9/2018. Figure 3 shows results from Otoka. Both raw (green colour) and humidity corrected (red colour) values are shown. Hourly averages of PM10 concentrations from BAM and MAQS sensors were well correlated (64\% for uncorrected and $67 \%$ for corrected MAQS*). Correlation for daily averages was (expectedly) higher: $79 \%$ for uncorrected and $82 \%$ for corrected values. Graph at the bottom of figure 3 shows daily averages of PM10 over time from BAM, uncorrected and corrected MAQS, from which we can see qualitatively good agreement.

Figure 4 shows results from Ilijaš. Similar correlation for hourly average values of PM10 was observed: $63 \%$ for uncorrected and $65 \%$ for humidity corrected readings. Daily averages, however, are $90 \%$ here which is almost sensational for this type of measurements. It is possible that shorter distance between MAQS and BAM sensor in Ilijaš eliminate all local differences in the atmosphere. This should be investigated carefully in the future. Qualitative agreement between BAM and MAQS sensors in Ilijaš was excellent, as we can from the last graph in figure 4.

The significance of humidity corrections for all graphs was noticeable, but not dramatic. This may be attributed for this particular part of the year; it would be interesting to reassess this in the winter period.

\section{Conclusion}

Application of low-cost dust sensors was demonstrated in real-life conditions at two locations: urban and suburban. It was shown that low-cost sensors can provide surprisingly good correlation with reference (and very expensive) instruments, if used correctly. Hourly average values of PM10 concentrations were similar for both locations, while daily average values reached $90 \%$ at suburban location, which is excellent. Qualitatively, there was good agreement between reference and low-cost sensors. Influence of the humidity was not very high in this particular period.

As a suggestion for further research we propose:

- strict collocation of sensors if possible,

- field campaign in winter period, with strong episodes of air pollution,

- further investigation of the influence of relative humidity on sensors.

\section{Acknowledgments}

This research was supported by the Ministry of Education of Sarajevo Canton and the University of Sarajevo Faculty of Mechanical Engineering. We would like to thank to Mr. Damir Muslić for his generous contribution to our project by writing core part of the in-house developed software. 

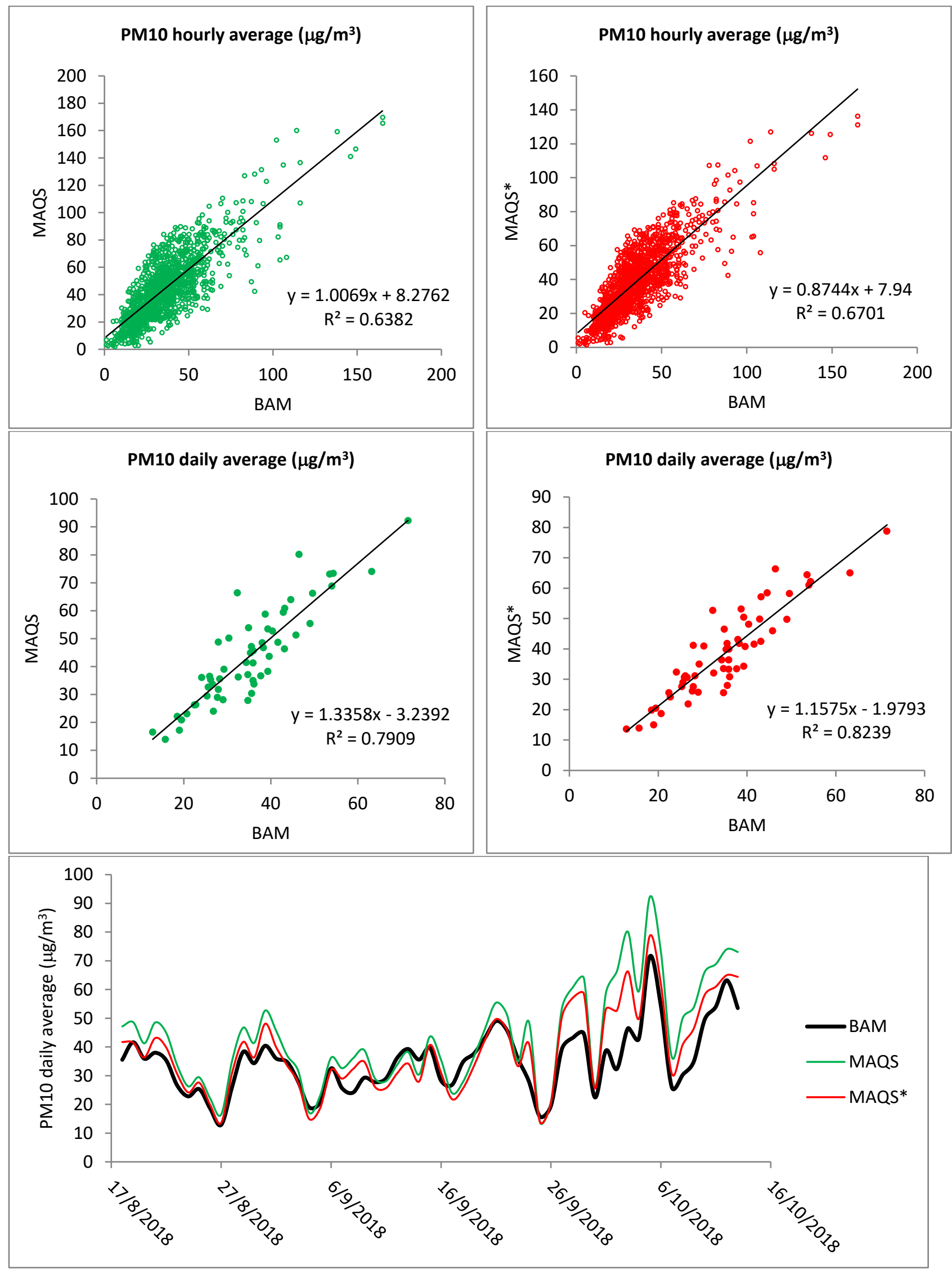

Fig. 3. Results from urban location (Otoka) 

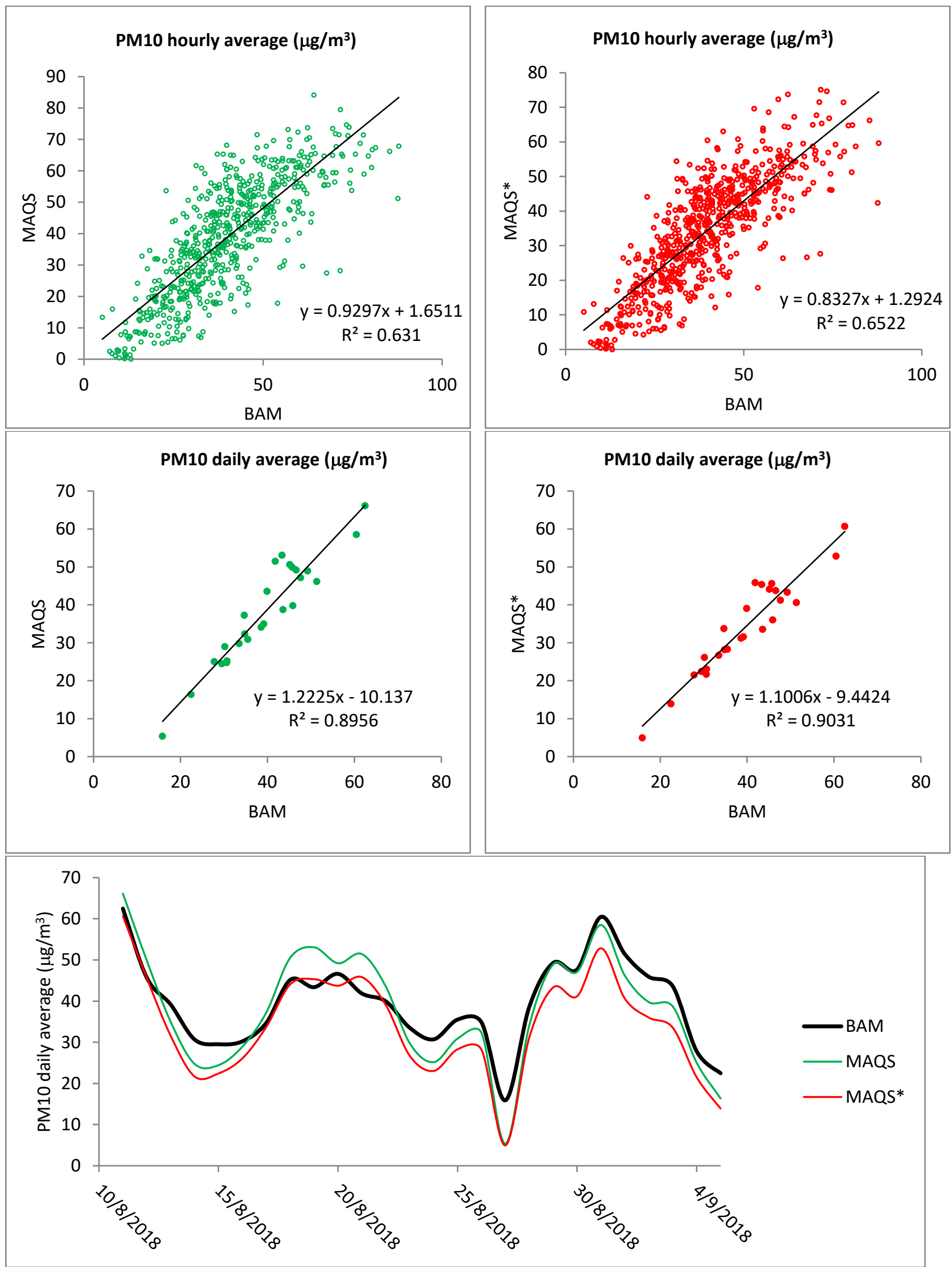

Fig. 4. Results from suburban location (Ilijaš) 


\section{References}

[1] https://www.epa.gov/pm-pollution/health-and-environmental-effects-particulate-matter-pm, (2018). United States Environmental Protection Agency, Accessed on: 2018-10-16

[2] Masic, A.; Pikula, B. \& Bibic, D. (2017). Mobile Measurements of Particulate Matter Concentrations in Urban Area, Proceedings of the 28th DAAAM International Symposium, pp.0452-0456, B. Katalinic (Ed.), Published by DAAAM International, ISBN 978-3-902734-11-2, ISSN 1726-9679, Vienna, Austria DOI: 10.2507/28th.daaam.proceedings.063

[3] Hergert W. \& Wriedt T. (2012). The Mie Theory. Springer, ISBN 978-3-642-28737-4, ISSN 0342-4111, DOI: https://doi.org/10.1007/978-3-642-28738-1, Berlin, Heidelberg

[4] ISO 13320:2009 (2009). Particle size analysis - Laser diffraction methods. International Organization for Standardization, Geneva, Switzerland.

[5] Streibl, N. (2017). Influence of Humidity on the Accuracy of Low-Cost Particulate Matter Sensors. Technical report. DOI: 10.13140/RG.2.2.21095.75683

[6] Jayaratne, R.; Liu, X.; Thai, P.; Dunbabin, M. \& Morawska, L. (2018). The Influence of Humidity on the Performance of a Low-cost Air Particle Mass Sensor and the Effect of Atmospheric Fog. Atmospheric Measurement Techniques, Atmospheric Measurement Techniques, 11, 4883-4890, DOI: https://doi.org/10.5194/amt-11-4883-2018

[7] Crilley, L. R.; Shaw, M.; Pound, R.; Kramer, L. J.; Price, R.; Young, S.; Lewis, A. C. \& Pope F. D.(2018). Evaluation of a Low-cost Optical Particle Counter (Alphasense OPC-N2) for Ambient Air Monitoring. Atmospheric Measurement Techniques, 11, 709-720, 2018, DOI: https://doi.org/10.5194/amt-11-709-2018

[8] Masic, A.; Musemic, R. \& Dzaferovic-Masic, E. (2016). Temperature Inversion Measurements in Sarajevo Valley Using Unmanned Aerial Vehicles, Proceedings of the 27th DAAAM International Symposium, pp.0423-0427, B. Katalinic (Ed.), Published by DAAAM International, ISBN 978-3-902734-08-2, ISSN 1726-9679, Vienna, Austria, DOI: $10.2507 / 27$ th.daaam.proceedings.062

[9] Masic, A. (2015). Unmanned Aerial Vehicle as Data Acquisition System. Journal of Trends in the Development of Machinery and Associated Technology. Vol. 19, No. 1, 2015, ISSN 2303-4009 (online), p.p. 181-184. 